Volume 9, No.5, September - October 2020

International Journal of Advanced Trends in Computer Science and Engineering

Available Online at http://www.warse.org/IJATCSE/static/pdf/file/ijatcse143952020.pdf

https://doi.org/10.30534/ijatcse/2020/143952020

\title{
The Prediction of Hotel Customer Loyalty using Machine Learning Technique
}

\author{
Youngkeun Choi ${ }^{1}$, Jae Won $\mathrm{Choi}^{2}$ \\ ${ }^{1}$ Associate Professor, Division of Business Administration, College of Business, Sangmyung University Seoul, \\ Korea, penking1@smu.ac.kr \\ ${ }^{2}$ Department of Computer Science, Erik Jonsson School of Engineering and Computer Science, University of \\ Texas at Dallas, Richardson, TX, USA, jxc190057@utdallas.edu
}

\begin{abstract}
The purpose of this study is to find and analyze the prediction of hotel customer loyalty using machine learning technique so that hotel companies can use the study to formulate possible solutions for customer relationship management. The corresponding variable information is drawn from a third-party website, international challenge on the popular internet platform Kaggle (www.kaggle.com). And, this study uses decision tree which is a powerful and popular machine learning algorithm to this date for predicting and classifying big data. For this, this study essentially had two primary approaches. Firstly, this paper intends to understand the role of variables in hotel customer loyalty prediction modeling better. Secondly, the study seeks to evaluate the predictive performance of the decision trees. In these results, first, we can predict their loyalty with a lot of individual factors of hotel customers. Second, for the full model, the accuracy rate is 0.989 , which implies that the error rate is 0.011 . This study provides some originality and value. First, this study extends the existing literature by empirically examining the combined impact of the variables on hotel customer loyalty prediction modeling. S, this application helps hotel companies to manage the personal records of the customers and also this will make the decision faster if they have the report of the user already with them.
\end{abstract}

Key words : Tourism industry, Customer loyalty prediction, Customer relationship management, Machine learning, Decision tree, Artificial intelligence.

\section{INTRODUCTION}

Machine learning is a field of computer science in which patterns of artificial intelligence are identified and computational learning theories are learned [1]. Machine learning is typically a change in systems that perform tasks related to artificial intelligence (AI). These tasks include recognition, analysis, planning, robot control, and prediction.
Explore the study and configuration of algorithms that can predict data. Machine learning is used to build programs with adjustment parameters to adapt to initial data and improve functionality. Machine learning is a technology that grows rapidly and works in the human mind. It represents a multistage record and can effectively address the selectivity dilemma [2].

Over the last decades, the fields of tourism, travel, hospitality and leisure have widely recognized the need for a customer-centric approach that primarily values tourists' needs, wants, preferences and requirements as major determinants in travel decisions in order to enhance both consumer satisfaction and the quality and memorability of the tourist experience [3]. Only very recently has an increasing amount of work related to the fields of data science grown to enrich these lines of research.

The increased profit from loyalty comes from reduced marketing costs, increased sales and reduced operational costs. Loyal customers are less likely to switch because of price and they make more purchases than similar non-loyal customers. Loyal customers will also help promote your hotel. They will provide strong word-of-mouth, create business referrals, provide references, and serve on advisory boards. Raman [4] states, loyal customers serve as a "fantastic marketing force" by providing recommendations and spreading positive word-of-mouth; those partnerships like activities are the best available advertising a company can get. Loyal customers increase sales by purchasing a wider variety of the hotel's products and by making more frequent purchases. Bowen and Shoemaker [5] found loyal hotel customers had higher food and beverage purchases than non-loyal customers. Finally, loyal customers cost less to serve, in part because they know the product and require less information

The purpose of this study is to find and analyze the prediction of hotel customer loyalty so that hotel companies can use the study to formulate possible solutions for customer relationship management. The methodology of the proactive approach and modeling techniques used in this paper can also be considered a roadmap for the reader to follow the steps 
taken in this study and to apply a procedure to identify the causes of many other problems. The aim of this paper is to provide quick, immediate and easy way to choose the deserving applicants. It can provide special advantages to the hotel. The hotel customer loyalty prediction system can can automatically calculate the weight of each features taking part in decision making and on new test data same features are processed with respect to their associated weight. A time limit can be set for the applicant to check whether his/her loyalty can be sanctioned or not. Hotel loyalty prediction system allows jumping to specific application so that it can be check on priority basis.

\section{RELATED STUDY}

\subsection{Tourism industry and data science}

Any tourism company (be it a hotel or an airline) needs to leverage its managerial and marketing strategies, tactics, and tools to achieve and maintain sustained competitive advantage. This is more critical in the current highly dynamic economic environment where competition is fierce and consumers are demanding and experienced. Increasingly, it is evident that it is extremely difficult, even for well-established companies, to cultivate and sustain a competitive advantage for a long period. We are going through an age of "temporary advantage" and "hyper competition" [6], where organizations need constant innovation to gain a temporary benefit and move ahead of the competition for a continued series of time periods [7].

In this context, big data can make a difference for the data science of tourism companies, help them make better strategic and tactical decisions, and create value. This is the reason why big data is increasingly a crucial component of the wider data science umbrella. However, research on the role of big data for data science in the hospitality and tourism literature is still scant and highly fragmented. Single research activities often take place in a rather isolated manner and tackle a very specific aspect or research question without looking at the whole picture and embedding new work into the overall scholarly and practical context. Such research practices, however, are common during the emergence of new research areas or phenomena. Therefore, in the current phase of development of hospitality and tourism research leveraging big data and data science, it is important and even overdue, to provide a clear overview of the different facets and issues of the wide research domain of data science and identify, discuss and integrate existing research activities leveraging big data into the overall context of the focal research domain. This is important in particular for two reasons. First, to stimulate but also to systematize further research activities. Second, to provide informational bases and overview on current application areas and utilization potentials for companies and stakeholders in the tourism domain.

\subsection{Hotel industry and customer royalty}

Hotel industry is based on those businesses which lead to profitability only because of their customer service, customer loyalty and customer satisfaction. Like other industries, this industry has also deviated from its traditional way of doing business and is actually now becoming more customer-focused and aimed at developing a positive and satisfying relationship with their customers. There is huge interference of Information technology and it underpins the reason for efficiency, meeting customer expectation and accuracy in services. Information technology is the most significant factor that is helping management of hotel industry in lowering their cost, time accuracy and increasing the operational excellences

Customer loyalty is defined as commitment toward preferred products or services. Customer loyalty is established by supporting a particular organization, regularly patronizing a certain provider, and increasing the frequency of purchases [8]. Loyal customers impact the profitability and overall success of the organization in three distinctive ways: (a) repeat purchases of products or services generate income for the organization, (b) the cost of marketing, advertising and operations are reduced, and (c) the spreading of favorable news and recommendations of services to others. Based on the importance and benefits of customer loyalty, many service organizations, especially hotels, allocate substantial resources to measure and monitor customer satisfaction, corporate image, and service quality. In addition, customer loyalty also has been viewed as the main tool to retain existing customers; retaining customer loyalty costs substantially less to maintain compared to acquiring new customers. Hence, the recommended approach to measure customer loyalty in hotels is based on the context of repeat purchase intention, price sensitivity and recommendations to friends and relatives.

\section{METHODOLOGY}

\subsection{Dataset}

The corresponding variable information is drawn from a third-party website, international challenge on the popular internet platform Kaggle (www.kaggle.com), which provides data in the title of 'Hotel booking demand' that was uploaded by Jesse Mostipak. This data set contains a single file which compares various booking information between two hotels: a city hotel and a resort hotel. The data is originally from the article Hotel Booking Demand Datasets, written by Nuno Antonio, Ana Almeida, and Luis Nunes for Data in Brief, Volume 22, February 2019. The data was downloaded and cleaned by Thomas Mock and Antoine Bichat for \#TidyTuesday during the week of February 11th, 2020. This data set contains the booking information of 119,386 customers for a city hotel and a resort hotel, and includes information such as when the booking was made, length of 
stay, the number of adults, children, and/or babies, and the number of available parking spaces, among other things. All personally identifying information has been removed from the data. This data set is ideal for anyone looking to practice their exploratory data analysis (EDA) or get started in building predictive models. The Kaggle asked participants to predict hotel booking demand. To help with algorithmic development, the organizers provided the types of a data stream for a large set of individual factors. These variables are listed and defined in Table 1.

Table 1: The variables in the dataset

\begin{tabular}{|c|c|c|}
\hline Categories & Variables & Measurement \\
\hline \multirow{13}{*}{$\begin{array}{l}\text { Individual } \\
\text { factors }\end{array}$} & hotel & $\begin{array}{l}\mathrm{H} 1=\text { Resort Hotel or } \mathrm{H} 2 \\
=\text { City Hotel }\end{array}$ \\
\hline & is_canceled & $\begin{array}{l}\text { Value indicating if the } \\
\text { booking was canceled (1) } \\
\text { or not (0) }\end{array}$ \\
\hline & lead_time & $\begin{array}{l}\text { Number of days that } \\
\text { elapsed between the } \\
\text { entering date of the } \\
\text { booking into the PMS } \\
\text { and the arrival date }\end{array}$ \\
\hline & $\begin{array}{l}\text { arrival_date_ye } \\
\text { ar }\end{array}$ & Year of arrival date \\
\hline & $\begin{array}{l}\text { arrival_date_m } \\
\text { onth }\end{array}$ & Month of arrival date \\
\hline & $\begin{array}{l}\text { arrival_date_w } \\
\text { eek_number }\end{array}$ & $\begin{array}{l}\text { Week number of year for } \\
\text { arrival date }\end{array}$ \\
\hline & $\begin{array}{l}\text { arrival_date_da } \\
\text { y_of_month }\end{array}$ & Day of arrival date \\
\hline & $\begin{array}{l}\text { stays_in_weeke } \\
\text { nd_nights }\end{array}$ & $\begin{array}{l}\text { Number of weekend } \\
\text { nights (Saturday or } \\
\text { Sunday) the guest stayed } \\
\text { or booked to stay at the } \\
\text { hotel }\end{array}$ \\
\hline & $\begin{array}{l}\text { stays_in_week_ } \\
\text { nights }\end{array}$ & $\begin{array}{l}\text { Number of week nights } \\
\text { (Monday to Friday) the } \\
\text { guest stayed or booked to } \\
\text { stay at the hotel }\end{array}$ \\
\hline & adults & Number of adults \\
\hline & children & Number of children \\
\hline & babies & Number of babies \\
\hline & meal & $\begin{array}{l}\text { Type of meal booked. } \\
\text { Categories are presented } \\
\text { in standard hospitality } \\
\text { meal packages: } \\
\text { Undefined/SC - no meal } \\
\text { package; BB - Bed \& } \\
\text { Breakfast; HB - Half } \\
\text { board (breakfast and one } \\
\text { other meal - usually } \\
\text { dinner); FB - Full board }\end{array}$ \\
\hline
\end{tabular}

\begin{tabular}{|c|c|}
\hline & $\begin{array}{l}\text { (breakfast, lunch and } \\
\text { dinner) }\end{array}$ \\
\hline country & $\begin{array}{l}\text { Country of origin. } \\
\text { Categories are } \\
\text { represented in the ISO } \\
3155-3: 2013 \text { format }\end{array}$ \\
\hline $\begin{array}{l}\text { market_segmen } \\
\mathrm{t}\end{array}$ & $\begin{array}{l}\text { Market } \\
\text { designation. } \\
\text { categories, the terment } \\
\text { "TA" means "Travel } \\
\text { Agents" and "TO" } \\
\text { means "Tour Operators" }\end{array}$ \\
\hline $\begin{array}{l}\text { distribution_ch } \\
\text { annel }\end{array}$ & $\begin{array}{l}\text { Booking distribution } \\
\text { channel. The term "TA" } \\
\text { means "Travel Agents" } \\
\text { and "TO" means "Tour } \\
\text { Operators" }\end{array}$ \\
\hline $\begin{array}{l}\text { previous_cance } \\
\text { llations }\end{array}$ & $\begin{array}{l}\text { Number of previous } \\
\text { bookings that were } \\
\text { cancelled by the } \\
\text { customer prior to the } \\
\text { current booking }\end{array}$ \\
\hline $\begin{array}{l}\text { previous_booki } \\
\text { ngs_not_cancel } \\
\text { ed }\end{array}$ & $\begin{array}{l}\text { Number of previous } \\
\text { bookings not cancelled } \\
\text { by the customer prior to } \\
\text { the current booking }\end{array}$ \\
\hline $\begin{array}{l}\text { reserved_room } \\
\text { _type }\end{array}$ & $\begin{array}{lr}\text { Code of room type } \\
\text { reserved. Code } & \text { is } \\
\text { presented instead } & \text { of } \\
\text { designation } & \text { for } \\
\text { anonymity reasons. } & \end{array}$ \\
\hline $\begin{array}{l}\text { assigned_room } \\
\text { _type }\end{array}$ & $\begin{array}{l}\text { Code for the type of room } \\
\text { assigned to the booking. } \\
\text { Sometimes the assigned } \\
\text { room type differs from } \\
\text { the reserved room type } \\
\text { due to hotel operation } \\
\text { reasons (e.g. } \\
\text { overbooking) or by } \\
\text { customer request. Code } \\
\text { is presented instead of } \\
\text { designation for } \\
\text { anonymity reasons. }\end{array}$ \\
\hline $\begin{array}{l}\text { booking_chang } \\
\text { es }\end{array}$ & $\begin{array}{l}\text { Number of } \\
\text { changes/amendments } \\
\text { made to the booking } \\
\text { from the moment the } \\
\text { booking was entered on } \\
\text { the PMS until the } \\
\text { moment of check-in or } \\
\text { cancellation }\end{array}$ \\
\hline deposit_type & $\begin{array}{l}\text { Indication on if the } \\
\text { customer made a deposit }\end{array}$ \\
\hline
\end{tabular}




\begin{tabular}{|c|c|c|}
\hline & & $\begin{array}{l}\text { to guarantee the booking. } \\
\text { This variable can assume } \\
\text { three categories: No } \\
\text { Deposit - no deposit was } \\
\text { made; Non Refund - a } \\
\text { deposit was made in the } \\
\text { value of the total stay } \\
\text { cost; Refundable - a } \\
\text { deposit was made with a } \\
\text { value under the total cost } \\
\text { of stay. }\end{array}$ \\
\hline & $\begin{array}{l}\text { days_in_waitin } \\
\text { g_list }\end{array}$ & $\begin{array}{l}\text { Number of days the } \\
\text { booking was in the } \\
\text { waiting list before it was } \\
\text { confirmed to the } \\
\text { customer }\end{array}$ \\
\hline & customer_type & $\begin{array}{l}\text { Type of booking, } \\
\text { assuming one of four } \\
\text { categories: Contract - } \\
\text { when the booking has an } \\
\text { allotment or other type of } \\
\text { contract associated to it; } \\
\text { Group - when the } \\
\text { booking is associated to a } \\
\text { group; Transient - when } \\
\text { the booking is not part of } \\
\text { a group or contract, and } \\
\text { is not associated to other } \\
\text { transient booking; } \\
\text { Transient-party - when } \\
\text { the booking is transient, } \\
\text { but is associated to at } \\
\text { least other transient } \\
\text { booking }\end{array}$ \\
\hline & $\mathrm{adr}$ & $\begin{array}{l}\text { Average Daily Rate as } \\
\text { defined by dividing the } \\
\text { sum of all lodging } \\
\text { transactions by the total } \\
\text { number of staying nights }\end{array}$ \\
\hline & $\begin{array}{l}\text { required_car_p } \\
\text { arking_spaces }\end{array}$ & $\begin{array}{l}\text { Number of car parking } \\
\text { spaces required by the } \\
\text { customer }\end{array}$ \\
\hline & $\begin{array}{l}\text { total_of_special } \\
\text { _requests }\end{array}$ & $\begin{array}{l}\text { Number of special } \\
\text { requests made by the } \\
\text { customer (e.g. twin bed } \\
\text { or high floor) }\end{array}$ \\
\hline $\begin{array}{l}\text { Customer } \\
\text { loyalty }\end{array}$ & $\begin{array}{l}\text { is_repeated_gu } \\
\text { est }\end{array}$ & $\begin{array}{l}\text { Value indicating if the } \\
\text { booking name was from } \\
\text { a repeated guest (1) or } \\
\text { not }(0)\end{array}$ \\
\hline
\end{tabular}


As we have discussed above decision tree classifier has been made on another algorithm know as CART short for classification and regression trees. In this algorithm we use Gini index as our cost function used to evaluate splits in the dataset. Here our target variable is indeed a binary variable so it will take two values (yes and no). And as we all know there can be 4 combinations. Now we need to figure out the Gini score which will give us a good idea of how we can split the data. If we can get the Gini score of 0 we can consider it to be a perfect separation whereas worst case scenario would a split of 50/50. Now the question arises how we can calculate Gini index value.

Now, if the target variable is a categorical variable with multiple levels, the Gini index will still be similar. So the steps for this method are the first compute of the Gini index for data-set. Then for every feature, we need to calculate the Gini index for all categorical values and take average information entropy for the current attribute and, in the end, calculate the Gini gain. After we are done with that, we can pick the best Gini gain attribute, and we need to repeat until we get our desired tree. And that is how the decision tree algorithm works.

DT classification methods involve building tree models that consist of a series of predictors. Each of these predictors (attributes) within a training set is split repetitively until pure subsets are obtained. This process of repetitive splitting is influenced by a particular entity's (i.e., customer) characteristics. The basic anatomy of a DT comprises of both a leaf node and a decision node. The leaf node represents a predictor variable and signifies the point where binary splits transpire. Leaf nodes are also known as internal nodes. The decision node, also known as the terminal node, represents the output variable (binary outcome variable) and graphically is depicted as the end of the branch. It is the terminal node that serves as the basis for churn prediction for it reports the category with the majority of cases. Extant literature has revealed that four major DT machine learning algorithms are commonly utilized: 1) Classification and Regression Trees (CART) 2) C4.5 3) chi-squared automatic interaction detection (CHAID) and 4) C5.0. DTs serve as the foundation of other tree methods like random forests and ensemble forests, which essentially involve aggregating multiple decision trees.

The process of binary splitting an attribute relies on selecting the right attributes to split. Correct attribute selection is dependent on calculating either entropy measures (C4.5) or choosing the Gini criterion (CART) based on the type of DT algorithm. DT analysis is quite popular due to simplicity, graphical layout, and ease of interpretation. DTs provide an appropriate schematic to model both quantitative and qualitative decision making questions without needing to create dummy variables or transformations. Moreover, DTs are also able to monitor non-linearities and are easy to compute. However, DTs also have their disadvantages. DT results may not always be as predictively accurate as other methods. Furthermore, minor changes in the dataset can result in non-robust predictions. However, this classification technique has been used frequently to model churn.

\subsection{Data mining models}

To survive in an increasingly competitive marketplace, many companies are turning to data mining techniques for decision prediction analysis. To manage customers effectively, it is important to build a more effective and accurate decision prediction model. Statistical and data mining techniques have been utilized to construct decision prediction models. The data mining techniques can be used to discover interesting patterns or relationships in the data, and predict or classify the behavior by fitting a model based on available data. In the case where the learning dataset and the test dataset are separated for machine learning, the test dataset must satisfy the following requirements. First, the training dataset and the test dataset must be created in the same format. Second, the test dataset should not be included in the training dataset. Third, the training dataset and the test dataset must be consistent in data. However, it is very difficult to create a test data set that meets these requirements. In data mining, various verification frameworks using one dataset have been developed to solve this problem. This study uses the Split Validation operator provided by RapidMiner to support this. The operator splits the input dataset into a training dataset and a test dataset to support performance evaluation. This study selects relative segmentation among the segmentation method parameters of this operator and uses $70 \%$ of input data as learning data.

\subsection{Performance evaluation}

Performance assessment uses training data to determine how well the generated model works. Performance measures can be divided into technical performance measures and heuristic measures. The technical performance measures to be used in this study show performance results by generating models from training data, processing test data into models, and comparing the class labels of original verification cases with predicted class labels. Measuring technical performance can be divided into supervised and unsupervised learning. The supervised learning used in this study is classified and regressed. The data used for this learning and test all have original class values. The performance is obtained by comparing and analyzing the original class values with the prediction results.

The classification problem is the most common data analysis problem. Various metrics have been developed to measure the performance of classification models. For classification problems of category type, accuracy, precision, recall, f-measure are used a lot. RapidMiner includes Performance (Classification), which measures performance indicators for common classification problems, and Performance (Binominal Classification), which provides performance indicators specific to binomial classification problems. The table 2 shows how these indicators are calculated. 
Table 2: Key performance indicators of binomial classification

\begin{tabular}{|l|l|l|l|}
\hline \multicolumn{2}{|c|}{} & \multicolumn{2}{|l|}{$\begin{array}{l}\text { Actual class (as determined by Gold } \\
\text { Standard) }\end{array}$} \\
\cline { 3 - 4 } & True & False \\
\hline $\begin{array}{l}\text { Predicted } \\
\text { class }\end{array}$ & Positive & True Positive & $\begin{array}{l}\text { False } \\
\text { Positive(Type } \\
\text { error) }\end{array}$ \\
\cline { 2 - 4 } & Negative & $\begin{array}{l}\text { False } \\
\text { Negative(Type } \\
\text { error) }\end{array}$ & True Negative \\
\hline
\end{tabular}

Precision $=\mathrm{TP} /(\mathrm{TP}+\mathrm{FP})$, Recall $=\mathrm{TP} /(\mathrm{TP}+\mathrm{FN})$, True negative rate $=\mathrm{TN} /(\mathrm{TN}+\mathrm{FP})$, Accuracy $=$ $(\mathrm{TP}+\mathrm{TN}) /(\mathrm{TP}+\mathrm{TN}+\mathrm{FP}+\mathrm{FN}), \quad$ F-measure $=$ $2 \cdot(($ precision $\cdot$ recall $) /($ precision + recall $))$

\section{RESULTS}

\subsection{Decision tree}

Figure 1 shows the classification tree for the full model after pruning the tree using cross-validation to avoid overfitting. The key variables in the full model analysis consist of 28 ones, as shown below, based on the criterion established with each of these variables. Hotel, is_canceled, lead_time, arrival_date_year, arrival_date_week_number, arrival_date_day_month, stays_in_weekend_nights, stays_in_week_nights, adults, previous_cancellation, previous_bookings_not_canceled, deposit_type, days_in_waiting_list, and adr influence is_repeated guest. Tables 3 illustrate each of the confusion matrix measures. For the full model, the accuracy rate is 0.989 , which implies that the error rate is 0.011 Among the customers who are predicted not to be repeated guest, the accuracy that would not be repeated guest was $99.43 \%$, and the accuracy that would be repeated guest was $81.79 \%$ among the patients who are predicted to be repeated guest.

Insert Figure 1 here

Table 3: Performance evaluation

\begin{tabular}{|c|c|c|c|}
\hline & True 0 & True 1 & $\begin{array}{c}\text { Class } \\
\text { precision }\end{array}$ \\
\hline Pred. 0 & 34443 & 198 & $99.43 \%$ \\
\hline Pred. 1 & 214 & 961 & $81.79 \%$ \\
\hline Class recall & $99.38 \%$ & $82.92 \%$ & \\
\hline
\end{tabular}

\section{CONCLUSION}

The main purpose of this paper is to test the accuracy of models and develop a new model to predict the hotel customer loyalty. To recap, this study essentially had two primary goals. Firstly, this paper intends to understand the role of variables in hotel customer loyalty prediction modeling better. Secondly, the study seeks to evaluate the predictive performance of the decision trees. Based on the findings reported above, a series of implications are drawn.

Concerning the first goal, the findings of the study suggest that assessing the role of variables is complex and that their influences vary according to the classification methods employed. The decision tree methods highlight the explanatory power as most important to the analysis. Therefore, collectively no unanimous conclusions can be drawn about which explanatory variables are most critical to hotel customer loyalty prediction for all the methods employed in totality. Yet, the findings of this study do shed some additional light on the customer's profile. The hotel companies should be seeking to predict hotel customer loyalty on the classification methods employed.

This study provides some research contributions and practical contributions. First, this study extends the existing literature by empirically examining the combined impact of the variables on hotel customer loyalty prediction modeling. A lot of studies have been reported about hotel customer loyalty prediction, but no one can say that researchers can create a universal human tool to predict hotel customer loyalty. Hotel customer loyalty prediction is so complex and connected to so many elements that researchers tend to use fewer elements and ignore the effects of other factors. Customer demographics are often changed and constantly monitored, which can cause problems with hotel companies and compromise personal information. Some studies looked at age, gender, and geographic location. But researchers are still unable to express cultural and behavioral factors that can affect hotel customer loyalty prediction. This study contributes to the literature regarding hotel customer loyalty prediction by providing a global model summarizing the hotel customer loyalty prediction determinants of customers' individual factors. Second, the methodology used in this paper can be viewed as a roadmap for the reader to follow the steps taken in this case study and to apply the one-day procedure to identify the causes of many other problems. This paper attempts to come up with the best-performing model for predicting hotel customer loyalty based on a limited set of features, including customers' individual factors. Machine learning technique such as decision tree, along with feature importance analyses, is employed to achieve the best results in terms of accuracy. With this methodology, this study identified a pattern of hotel customer loyalty prediction.

Practically, this application helps hotel companies to manage the personal records of the customers and also this will make the decision faster if they have the report of the user already 
with them. Basically, a prototype of the model is described in the paper which can be used by the organizations for making the correct or right decision to recognize the loyalty of the hotel customers. Futhermore, this paper provides practical implications to the managing authority of hotel company. Because whole process of prediction is done privately, no stakeholders would be able to alter the processing. Result against particular customer can be send to various departments of hotel so that they can take appropriate action on application. This helps all others department to carried out other formalities.

In the proposed system, I have a database to store the records of the customers, and when the count of the customers increases means, more data will be generated, and the storage will become a problem. Therefore, in a future release, there will be a cloud facility to store all the records in the cloud. Therefore, the data protected safely and can be retrieved from anywhere if we have the right to access the data. The smart device will be synced with our application in the future release. Therefore, the customer's real-time transaction record will be monitored, and in the case of booking needs, the hotel companies will get alerted.

In the future, the machine learning model will make use of a larger training dataset, possibly more than a million different data points maintained in an electronic transaction record system. Although it would be a huge leap in terms of computational power and software sophistication, a system that will work on artificial intelligence might allow the financial practitioner to decide the best-suited decisiont for the concerned customers as soon as possible. A software API can be developed to enable health websites and apps to provide access to the customer free of cost. The probability prediction would be performed with zero or virtually no delay in processing.

\section{REFERENCES}

1. J. Simon. Artificial intelligence: scope, players, markets and geography. Digital Policy, Regulation and Governance, Vol. 21, No. 3, pp. 208-237, 2019.

2. Y. Le Cun, Y. Bengio, and G. E. Hinton. Deep learning. Nature, Vol. 521, pp. 436-444, 2015.

3. A. Correia, M. Kozak, and J. Ferradeira. From tourist motivations to tourist satisfaction. International. Journal of Culture, Tourism and Hospitality Research, Vol. 7, No. 4, pp. 411-424, 2013.

4. P. Raman. Way to create loyalty. New Straits Times, Kuala Lumpur, 17 August,1999

5. J. T. Bowen and S. Shoemaker. Loyalty: a strategic commitment?. Cornell Hotel and Restaurant Administration Quarterly, February, pp. 12-25, 1998.

6. R. A. D'Aveni, G. B. Dagnino, and K. G. Smith. The Age of Temporary Advantage. Strategic Management Journal, Vol. 31, No. 13, pp. 1371-1385, 2010.
7. M. M. Mariani, M. Di Felice, and M. Mura. Facebook as a destination marketing tool: Evidence from Italian regional Destination Management Organizations. Tourism Management, Vol. 54, pp. 321-343, 2016.

8. H. Wilkins, B. Merrilees, and C. Herington. The determinants of loyalty in hotels. Journal of Hospitality Marketing \& Management, Vol. 19, pp. 1-21, 2009.

9. J. M. Gonzalez-Cava, J. A. Reboso, J. L. Casteleiro-Roca, J. L. Calvo-Rolle, and J. A. M. Pérez. A Novel Fuzzy Algorithm to Introduce New Variables in the Drug Supply Decision-Making Process in Medicine. Complexity, https://doi.org/10.1155/2018/9012720, 2018. 


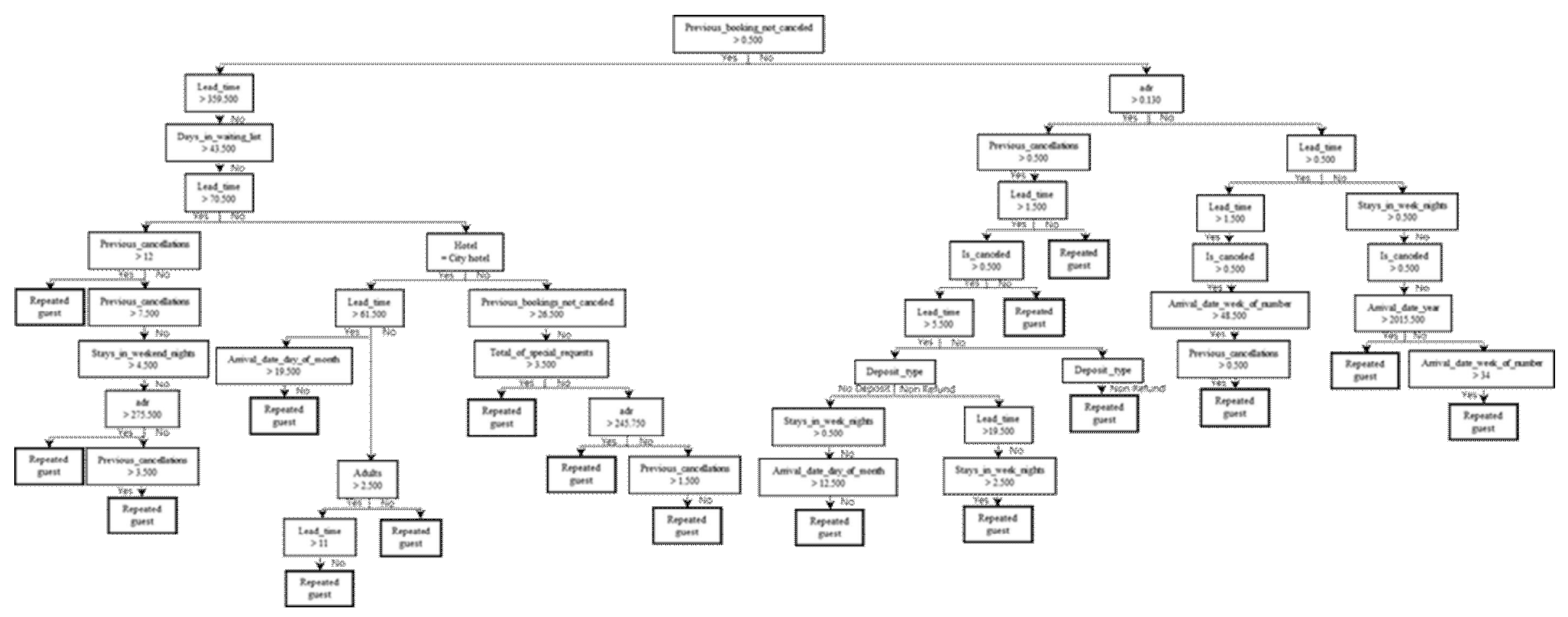

Figure 1: Classification Tree for the Full Model 